\title{
Caracterização fenotípica de ovinos da raça Santa Inês no Estado do Piauí
}

\author{
Phenotypic characterization of Santa Inês sheep in the State of Piauí
}

\author{
BIAGIOTTI, Daniel $^{1 *}$; SARMENTO, José Lindenberg Rocha ${ }^{2}$; Ó, Alan Oliveira do ${ }^{1}$; \\ RÊGO NETO, Aurino de Araújo ${ }^{1}$; SANTOS, Gleyson Vieira dos ${ }^{3}$; SANTOS, Natanael \\ Pereira da Silva ${ }^{1}$; TORRES, Tatiana, Saraiva ${ }^{1}$; NERI, Vanessa dos Santos ${ }^{2}$
}

\author{
${ }^{1}$ Universidade Federal do Piauí, Programa de Pós-Graduando em Ciência Animal Teresina, Piauí, Brasil. \\ ${ }^{2}$ Universidade Federal do Piauí, Bom Jesus, Piauí, Brasil. \\ ${ }^{3}$ Universidade Federal do Piauí, Programa de Pós-Graduação em Zootecnia, Bom Jesus, Piauí, Brasil. \\ *Endereço para correspondência: danielbiagiotti@hotmail.com
}

\section{RESUMO}

Objetivou-se, com esse trabalho, estudar a caracterização morfométrica de ovinos da raça Santa Inês para auxílio à conservação genética desta raça em diferentes microrregiões do Estado do Piauí, de modo a contribuir com a conservação da raça. Para isso, foram coletadas medidas morfométricas em ovinos oriundos de diferentes microrregiões do Estado do Piauí. As características de medidas corporais coletadas foram a altura de cernelha, a altura de garupa, a circunferência torácica, o comprimento corporal e o comprimento de orelha. Foram avaliadas as médias das medidas por microrregião e através da análise de componentes principais, com auxílio do PROC PRINCOMP do SAS, foi possível agrupar as populações com base em medidas de similaridade. Os grupos foram formados através da análise de agrupamento pelo método Ward. A partir das análises foi encontrada diversidade fenotípica nos ovinos Santa Inês criados no Estado do Piauí, sendo formada por um grupo de animais maiores, localizados nas microrregiões de Floriano, Médio Parnaíba Piauiense, Campo Maior e Teresina; um grupo de animais de tamanho intermediário, porém com comprimento corpora e circunferência torácica maiores e orelhas pequenas, localizado na microrregião de São Raimundo Nonato, outro grupo com tamanho intermediário e orelhas grandes e o último grupo composto por animais menores, localizados nas microrregiões do Litoral Piauiense e Valença. As medidas que mais contribuíram para a análise de componente principal foram as medidas de altura de garupa, altura de cernelha e comprimento corporal.

Palavras-chaves: análise multivariada, caracterização, conservação genética, morfometria.

\section{SUMMARY}

The objective of this work was to study the morphometric characterization of Santa Inês sheep to aid the conservation genetics of this breed in different micro-regions of the State of Piauí. For this, morphometric measurements have been collected in sheep from different micro-regions of the state of Piauí. The body measurements, collected were withers height, hip height, chest circumference, body length and ear length. The averages of the measures obtained in each micro-region were evaluated and by the use of the principal component analysis, helped by the SAS PROC PRINCOMP, it was possible to group populations based on similarity measures. The groups were formed relying on a cluster analysis by Ward method. Considering the analyzes, phenotypic diversity was found in Santa Ines sheep reared in the state of Piaui; being formed by a group of larger animals, located in the region of Floriano, Médio Parnaíba Piauiense, Teresina and Campo Maior; another group of animals of intermediate size, but with greater body length and girth circumference and small ears, located in the microregion of São Raimundo Nonato, another group with intermediate size and big ears and the last 
group of smaller animals located in the region of the Litoral Piauiense and Valença. The measures that contributed mostly for the principal component analysis were measures of hip height, withers height and body length.

Keywords: characterization, conservation genetics, morphometry, multivariate analysis.

\section{INTRODUÇÃO}

O desenvolvimento no Brasil de raças deslanadas, como a Santa Inês, apresentou-se como alternativa interessante para a melhora da eficiência dos sistemas de produção de carne ovina (COSTA et al., 2006).

Embora a raça Santa Inês tenha despertado o interesse dos criadores, principalmente, em função do seu porte e da velocidade de crescimento quando comparada a outras raças deslanadas, do ponto de vista biológico, é um material genético novo e, de certa forma, ainda pouco conhecido, necessitando de melhoria genética, principalmente, quanto à qualidade da carcaça, à eficiência reprodutiva, à habilidade materna e à resistência a endoparasitas.

A origem dos ovinos Santa Inês ainda é bastante discutida, pois é considerada uma mistura de raças, entretanto Paiva et al. (2005) reforçam a ideia de uma raça naturalizada, proveniente da Bahia, porém maiores discussões se fazem necessárias naquilo que se refere à formação da raça Santa Inês, se considerarmos a necessidade de se realizar a caracterização da raça, utilizando medidas corporais, mensuradas no animal, que permitam que se encontre o padrão fenotípico dos animais dessa raça criados no Estado do Piauí.

As características morfométricas podem possibilitar o agrupamento os animais de uma mesma espécie em raças distintas (OLIVEIRA et al., 2006; DOSSA et al., 2007). Segundo Barbosa et al. (2010) ao fato de as características de importância econômica, utilizadas para avaliar os indivíduos ou genótipos, serem de natureza quantitativa e, portanto, sujeitas a diferentes bases genéticas e graus de influência de ambiente, torna-se difícil interpretar o conjunto de características, por meio de análises univariadas.

O estudo da diversidade é proposto pela análise de características morfométricas em conjunto através da análise multivariada, cuja vantagem é a aplicação em vários tipos de dados, podendo ser aplicada a diversos marcadores de diversidade. A análise de agrupamento permite relacionar a estimativa de uma medida de dissimilaridade entre os indivíduos.

Assim, objetivou-se estudar a caracterização morfométrica dos ovinos Santa Inês criados em diferentes microrregiões do Estado do Piauí por meio de medidas morfométricas, de modo a contribuir com o melhoramento genético e conservação da raça.

\section{MATERIAL E MÉTODOS}

Os dados foram coletados em rebanhos de ovinos da raça Santa Inês provenientes de diferentes microrregiões do Estado do Piauí. As microrregiões visitadas foram definidas, segundo IBGE como Litoral Piauiense, Teresina, Campo Maior, Valença do Piauí, Médio Parnaíba Piauiense, São Raimundo Nonato, Floriano e Alto Médio Gurguéia. A importância da criação de ovinos foi fundamental na escolha dessas microrregiões, pois nelas são encontrados animais criados para fins de exposição e também animais para a criação comercial. Com isso, buscou-se encontrar a maior representatividade da raça no Estado. O contato com os criadores foi realizado via telefone ou 
pessoalmente na propriedade para que fosse feita a solicitação de autorização da coleta dos dados necessários à realização deste trabalho.

Foram coletadas informações, no período de 2009 a 2011, de medidas morfométricas em 977 fêmeas adultas, acima de dois anos de idade, de ovinos da raça Santa Inês criadas nos municípios de Angical, Aroazes, Bom Jesus, Campo Maior, Cristino Castro, Dirceu Arcoverde, Elesbão Veloso, Floriano, Palmeira do Piauí, Piracuruca, Redenção do Gurguéia, Santa Cruz dos Milagres, São Pedro, São Raimundo Nonato e Teresina.

A decisão por coletar informações em animais adultos foi tomada baseada em Bueno et al. (2002) que afirmam não haver mais variação considerável no comprimento corporal quando o animal atinge a maturação esquelética. Sendo realizada análise de variância foi evidenciado que a idade coletada dos animais não foram significativas para as medidas corporais. A idade foi estimada segundo cronologia dentária dos animais.

As medidas morfométricas tomadas foram as alturas de cernelha (AC) e garupa (AG), a circunferência torácica (CIRC), o comprimento de orelhas (CO) e o comprimento do animal (CC), todas em centímetros. A mensuração das medidas morfométricas corporais foram realizadas com o auxílio de uma fita métrica, com o animal mantido em posição correta de aprumo. A altura de cernelha correspondeu à medida entre $\mathrm{o}$ ponto mais alto da cernelha até a extremidade distal do membro anterior; a altura da garupa compreendeu a medida entre o ponto mais alto da garupa do animal até a extremidade do membro posterior; o comprimento de orelha foi tomado da base até a extremidade da orelha; o comprimento do animal foi mensurado da ponta da escápula até a ponta do ísqueo; e a circunferência torácica foi medida passando a fita em torno do tórax do animal, próxima às axilas. Houve preocupação em coletar as medidas com os animais em jejum para evitar que o distendimento do rúmem pudesse contribuir para a confusão de medidas.

Após a coleta, os dados foram armazenados em planilhas eletrônicas para posterior análise. Utilizando o logiciário estatístico Statistical Analysis System (SAS Institute, 2002) foram realizadas as análises estatísticas descritivas simples (média, desvio padrão e coeficiente de variação) através do procedimento MEANS; a análise de variância fora realizada pelo PROC GLM e as médias foram comparadas através do teste Student Newman Keuls (SNK) a $5 \%$ de significância.

Para o estudo de diversidade fenotípica foi realizada a análise de componentes principais, com o auxílio do PROC PRINCOMP do SAS, o que permitiu agrupar as populações com base na relação entre as características medidas. A distribuição espacial dos indivíduos, pelos componentes principais, permite identificar os grupos genéticos mais similares, importantes, por exemplo, na formação dos grupos das microrregiões e ainda, uma primeira visualização do grau de uniformidade entre indivíduos dentro de cada população.

O método de análise de componentes principais, utilizando a matriz de correlação, consiste em transformar um conjunto de variáveis simples em um novo conjunto de variáveis transformadas, sendo que cada componente principal é uma combinação linear das medidas corporais originais, independentes entre si e estimados com objetivos de reter o máximo de informação em termos de variação total contida nos dados originais. 


$$
C P=a_{i 1} X_{1}+a_{i 2} X_{2}+\ldots+a_{i n} X_{n}=\sum_{j=1}^{p} a_{i j} z_{j}
$$

com $i$ e $j=1,2, . ., \mathrm{n}$

Após encontrar os componentes principais, pode-se afirmar que $\mathrm{o}$ primeiro componente $\mathrm{CP}_{1}$ é o que explica a maior variância existente na população, o segundo componente explica a segunda maior variância existente e, assim, sucessivamente, até completar o conjunto $\mathrm{n}$ de componentes principais.

Assim, a ideia principal por trás desse procedimento é de que poucos, dentre os primeiros componentes principais, expliquem a maior variabilidade dos dados originais para que racionalmente possa-se descartar os demais componentes, reduzindo o número de variáveis a serem analisadas.

Foi necessária a padronização das variáveis, pois a estrutura de dependência de $\mathrm{X}_{\mathrm{j}}$ foi dada pela matriz de correlação $\mathrm{R}$, sendo padronizada para media igual a zero e desvio-padrão igual a um. Dessa forma, a diferença das escalas de medidas das variáveis foi retirada pelo uso de variáveis reduzidas (variáveis padronizadas).

Os autovalores da matriz de correlação corresponderam às variâncias de cada componente, e os autovetores normalizados corresponderam aos coeficientes de ponderação das características padronizadas. Para descarte de variáveis, na análise de componentes principais a partir da matriz de correlação estabeleceu-se que o número de variáveis descartadas deve ser igual ao de componentes cuja variância (autovalor) é inferior a 0,7.

A importância relativa de um componente principal foi avaliada pela percentagem de variância total que ele explica, ou seja, a percentagem de seu autovalor em relação ao total dos autovalores de todos os componentes.
A dissimilaridade deu-se na relação entre pares de populações, de forma que, uma alta dissimilaridade entre populações indique que as populações em questão sejam distantes, tendo como base as medidas morfométricas amostradas (RENCHER, 2002). Calculada a dissimilaridade, foi utilizado o método de agrupamento Ward para o cálculo do menor aumento da variância intra-grupo para gerar os agrupamentos e, consequentemente, os dendrogramas. $\mathrm{O}$ método de Ward não calcula distâncias entre grupos. Mas, para a formação dos grupos foi feita a maximização da homogeneidade dentre eles, ou a minimização do total das somas de quadrados dentro de cada grupo, também conhecida como soma de quadrados de erros. Em cada passo do procedimento, foram formados grupos de tal modo que a solução resultante tenha tido a menor soma de quadrados dentro de grupos. Para a escolha adequada do método de agrupamento, calculou-se o valor do coeficiente de correlação cofenética (CCC) proposto por Sokal \& Rohlf (1962). Sendo que quanto maior o valor obtido para CCC, menor será a distorção provocada pelo agrupamento. Segundo Rohlf (1970), na prática, dendrogramas com CCC menor que 0,7 indicam a inadequação do método de agrupamento para resumir a informação do conjunto de dados.

\section{RESULTADOS E DISCUSSÃO}

Os valores de médias e desvios padrão (Tabela 1) foram obtidos utilizando as medidas das fêmeas de ovinos Santa Inês, sendo que as médias das medidas estão de acordo com a Arco (Associação Brasileira de Criadores de Ovinos), naquilo que se refere à raça Santa Inês, os valores de desvio padrão 
são de baixa magnitude, o que resultou, também, em baixos coeficientes de variação. Os coeficientes de variação foram mais altos nas medidas de comprimento de orelha e circunferência torácica.

Tabela 1. Médias, desvios padrão (DP) e coeficiente de variação (CV) das características biométricas dos ovinos da raça Santa Inês no Estado do Piauí

\begin{tabular}{lccc}
\hline \multirow{2}{*}{ Medidas } & \multirow{2}{*}{ Média $(\mathrm{cm})$} & Fêmeas $(\mathrm{N}=977)$ & \multirow{2}{*}{ CV $(\%)$} \\
\cline { 3 - 3 } & & DP $(\mathrm{cm})$ & 6,87 \\
Altura de Garupa & 71,37 & 4,91 & 7,36 \\
Altura de Cernelha & 71,35 & 5,25 & 9,34 \\
Comprimento Corporal & 70,27 & 6,56 & 12,58 \\
Comprimento de Orelha & 15,81 & 1,99 & 11,06 \\
Circunferência torácica & 86,39 & 9,55 & \\
\hline
\end{tabular}

Os resultados das médias obtidas corroboram os observados por Carneiro et al. (2010) que encontraram médias próximas às obtidas neste estudo para as mesmas medidas em ovinos Santa Inês no Brasil. Em estudo da caracterização de ovinos Santa Inês em Teresina e Campo Maior, Costa Júnior et al. (2006) também encontraram resultados próximos às médias encontradas neste trabalho, sendo que as medidas de altura de cernelha e altura de garupa juntamente com comprimento corporal são bastante próximas indicando harmonia no tamanho e conformação do animal.

Conforme a divisão das microrregiões do Estado do Piauí, foram estimadas as médias e os desvios padrão para as características (Tabela 2).

Tabela 2. Médias e número de observações $(\mathrm{N})$ para as características biométricas de ovinos da raça Santa Inês encontrados nas diferentes microrregiões do Estado do Piauí

\begin{tabular}{lcccccc}
\hline Microrregiões & N & $\begin{array}{c}\text { Altura } \\
\text { Cernelha }\end{array}$ & $\begin{array}{c}\text { Altura } \\
\text { Garupa }\end{array}$ & $\begin{array}{c}\text { Comprimento } \\
\text { Corporal }\end{array}$ & $\begin{array}{c}\text { Comprimento } \\
\text { Orelha }\end{array}$ & $\begin{array}{c}\text { Circunferência } \\
\text { Torácica }\end{array}$ \\
\cline { 2 - 6 } & & Média & Média & Média & Média & Média \\
\hline Alto Médio & 340 & $71,76^{\mathrm{ab}}$ & $71,43^{\mathrm{b}}$ & $69,28^{\mathrm{b}}$ & $15,88^{\mathrm{a}}$ & $84,90^{\mathrm{cd}}$ \\
Gurguéia & 108 & $73,82^{\mathrm{a}}$ & $74,11^{\mathrm{a}}$ & $74,24^{\mathrm{a}}$ & $16,59^{\mathrm{a}}$ & $94,05^{\mathrm{a}}$ \\
Teresina & 44 & $73,15^{\mathrm{a}}$ & $73,75^{\mathrm{a}}$ & $72,28^{\mathrm{a}}$ & $16,07^{\mathrm{a}}$ & $89,31^{\mathrm{b}}$ \\
Floriano & 36 & $73,89^{\mathrm{a}}$ & $73,10^{\mathrm{ab}}$ & $73,62^{\mathrm{a}}$ & $16,57^{\mathrm{a}}$ & $88,00^{\mathrm{bc}}$ \\
Médio Parnaíba & 178 & $71,82^{\mathrm{ab}}$ & $72,90^{\mathrm{ab}}$ & $72,06^{\mathrm{a}}$ & $16,61^{\mathrm{a}}$ & $86,97^{\mathrm{bc}}$ \\
Piauiense & 85 & $70,47^{\mathrm{bc}}$ & $66,65^{\mathrm{d}}$ & $68,08^{\mathrm{b}}$ & $13,62^{\mathrm{c}}$ & $89,01^{\mathrm{b}}$ \\
Campo Maior & 152 & $68,13^{\mathrm{d}}$ & $69,37^{\mathrm{c}}$ & $68,41^{\mathrm{b}}$ & $15,00^{\mathrm{b}}$ & $82,30^{\mathrm{de}}$ \\
São Raimundo & \multirow{2}{*}{$\begin{array}{l}\text { Nonato } \\
\text { Valença }\end{array}$} & $69,08^{\mathrm{cd}}$ & $69,38^{\mathrm{c}}$ & $65,79^{\mathrm{c}}$ & $16,38^{\mathrm{a}}$ & $80,38^{\mathrm{e}}$ \\
Litoral & 34 & & & &
\end{tabular}

Médias seguidas de mesma letra na coluna não diferem estatisticamente $(\mathrm{P}>0,05)$ pelo teste StudentNewman-Keuls 
Os animais criados nas microrregiões de São Raimundo Nonato, Valença e no Litoral Piauiense apresentaram porte menor que os animais criados nas demais microrregiões, sugerindo que nas microrregiões de São Raimundo Nonato e Valença, por possuírem clima de semiárido e escassez de alimentos, os animais possuem menor tamanho, o que é vantajoso, pois animais menores possuem baixa taxa de mantença necessária para sobreviver em condições adversas e os animais da microrregião do Litoral Piauiense podem ser menores devido ao processo de seleção ao qual estão submetidos, adotados pelos criadores desta localidade. Já os animais das microrregiões de Teresina, Floriano e Médio Parnaíba Piauiense obtiveram maiores tamanhos, provavelmente por ser uma região mais avançada economicamente e os produtores possuírem animais adquiridos em exposições, concordando com Costa Júnior et al. (2006) que afirma que animais criados em grandes centros possuem maior tamanho corporal.

As microrregiões que obtiveram resultados menores de tamanho $\mathrm{e}$ comprimento são caracterizadas pelo isolamento geográfico, locais em que a seleção natural é mais evidenciada e também a interferência do homem na seleção é menos evidente, diferentemente das microrregiões que obtiveram maiores valores de tamanho, nas quais os criadores dispõem de maior tecnologia e interferem mais no manejo.

Através da análise de componente principal (Figura 1), na qual os dois primeiros componentes explicam mais de $95 \%$ da variação total existente, foram calculados os escores relativos do primeiro componente em relação à jésima microrregião.

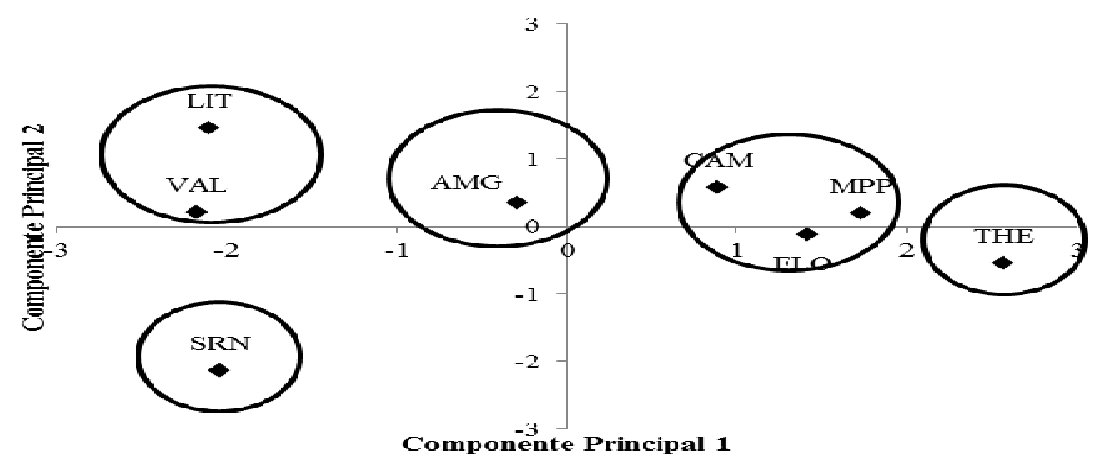

SRN:São Raimundo Nonato; VAL: Valença do Piauí; LIT: Litoral Piauiense; AMG: Alto Medio Gurguéia; CAM:Campo Maior; FLO:Floriano; MPP: Médio Parnaíba Piauiense; THE:Teresina

Figura 1. Gráfico contendo as coordenadas dos dois principais componentes em relação às microrregiões do Estado do Piauí

Com a utilização do plano cartesiano, no qual em seus eixos estão os valores dos dois primeiros componentes principais, pode-se perceber que as microrregiões que apresentaram menores médias de tamanho dos animais estão geograficamente mais próximas, como São Raimundo Nonato e Valença, esses grupos são compostos por animais de menor altura $\mathrm{e}$ 
comprimento corporal, porém os animais da raça Santa Inês criados na microrregião de São Raimundo Nonato possuem a característica de circunferência torácica maior, quando comparados a estas duas microrregiões. De acordo com Silva et al. (2007), quanto maior a circunferência torácica do animal, maior será a sua habilidade de ganho de peso. Animais com maior circunferência torácica possuem maior capacidade respiratória e de ingestão de matéria seca.

Como a utilização dos componentes principais, tais como a ferramenta de agrupamento, é baseada apenas na visualização gráfica, ou seja, sem embasamento estatístico, foi feita a análise de agrupamento segundo $\mathrm{o}$ método de Ward (Figura 2). Os valores de bootstap de cada ramificação do dendrograma, tendo sido representados somente os valores acima de $50 \%$ de consistência. Com valores acima de $50 \%$, é possível dizer que o agrupamento possui consistência em sua formação. Em relação à avaliação do grau de ajuste entre as matrizes de dissimilaridade e as matrizes resultantes dos agrupamentos, para a formação dos dendrogramas, foi estimado o coeficiente de correlação cofenética (CCC), cujo valor obtido utilizando-se o método de agrupamento Ward foi de 0,77. A partir desse coeficiente, pode-se dizer que a distância euclidiana média padronizada foi adequada para resumir a informação do conjunto de dados, visto que se tem recomendado valores de CCC acima de 0,70 (ROHLF, 1970).

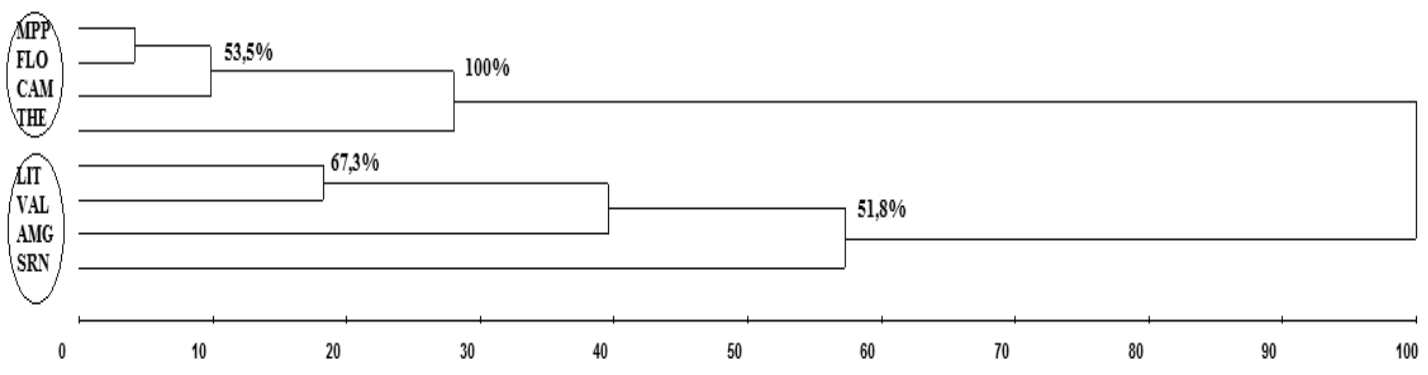

SRN:São Raimundo Nonato; VAL: Valença do Piauí; LIT: Litoral Piauiense; AMG: Alto Medio Gurguéia; CAM:Campo Maior; FLO:Floriano; MPP: Médio Parnaíba Piauiense; THE:Teresina

Figura 2. Dendrograma do agrupamento das microrregiões do Estado do Piauí pelo método Ward com os valores e bootstrap acima de 50\% indicados em cada nó

A partir da análise de agrupamento percebe-se a formação de dois grupos formados entre as microrregiões, sendo o primeiro grupo representado pelas microrregiões de Valença, Litoral Piauiense, Alto Médio Gurguéia e São Raimundo Nonato e o segundo composto pelas microrregiões de Floriano, Médio Parnaíba Piauiense, Campo Maior e Teresina, as microrregiões do segundo grupamento estão próximas geograficamente e, em comum, possuem o fato de estarem próximas a grandes centros responsáveis por difusão de tecnologia e interferência do homem. Com exceção da microrregião de Floriano, as demais microrregiões pertencentes ao segundo grupo estão localizadas no Norte do Estado. Enquanto o primeiro grupo possui os animais pertencentes às 
microrregiões do Sul do estado, com exceção do Litoral Piauiense.

O grupo 1 é composto por animais de menor porte, característica de animais naturalizados, com o comprimento de orelha menor que o segundo grupo. Os animais pertencentes ao grupo dois são compostos por animais maiores, mais compridos e com costelas bem arqueadas, característico de animais especializados na produção de carne (Tabela 3).

Tabela 3. Médias para as características biométricas de ovinos da raça Santa Inês encontrados nos diferentes grupos segundo critério de microrregiões do Estado do Piauí

\begin{tabular}{lcccccc}
\hline \multirow{2}{*}{ Grupo } & \multirow{2}{*}{ Microrregião } & $\begin{array}{c}\text { Altura } \\
\text { Garupa }\end{array}$ & $\begin{array}{c}\text { Altura } \\
\text { Cernelha }\end{array}$ & $\begin{array}{c}\text { Comp. } \\
\text { Corporal }\end{array}$ & $\begin{array}{c}\text { Comp. } \\
\text { Orelha }\end{array}$ & $\begin{array}{c}\text { Circunf. } \\
\text { Torácica }\end{array}$ \\
\cline { 3 - 7 } & & Média & Média & Média & Média & Média \\
\hline \multirow{2}{*}{1} & LIT, VAL, & $70,53^{\mathrm{b}}$ & $70,14^{\mathrm{b}}$ & $68,71^{\mathrm{b}}$ & $15,38^{\mathrm{b}}$ & $84,57^{\mathrm{b}}$ \\
\multirow{2}{*}{2} & $\begin{array}{c}\text { AMG e SRN } \\
\text { CAM, FLO, }\end{array}$ & $72,78^{\mathrm{a}}$ & $73,38^{\mathrm{a}}$ & $72,89^{\mathrm{a}}$ & $16,54^{\mathrm{a}}$ & $89,44^{\mathrm{a}}$ \\
\hline
\end{tabular}

Médias seguidas de mesma letra na coluna não diferem estatisticamente $(\mathrm{P}>0,05)$ pelo teste StudentNewman-Keuls SRN = São Raimundo Nonato; VAL = Valença do Piauí; LIT = Litoral Piauiense; AMG = Alto Medio Gurguéia; CAM = Campo Maior; FLO = Floriano; MPP = Médio Parnaíba Piauiense; THE $=$ Teresina

O município que possui maiores médias para as características corporais avaliadas é Angical, o que pode ser explicado devido ao fato dos criadores visitados terem adquirido animais em leilões. Nesses locais, há uma valorização maior, por parte dos organizadores, pelo tamanho do animal. A localização geográfica desse município é próxima à capital Teresina, onde são realizados esses eventos. Existem também animais com tamanho intermediário e animais com menor tamanho, sugerindo a diversidade presente na raça Santa Inês.

Os animais com menores tamanho pertencem às cidades de Dirceu Arcoverde e Santa Cruz dos Milagres, cidades pertencentes à microrregião de São Raimundo Nonato e Valença, reforçando a hipótese de isolamento geográfico e menor interferência do homem no manejo de cruzamentos. Os animais dos municípios de Bom Jesus,
Campo Maior, Cristino Castro, Floriano e Redenção do Gurguéia apresentam médias estatisticamente iguais para a maioria das medidas morfométricas, indicando a formação de um grupo de animais semelhantes, já os animais do município de São Raimundo Nonato possuem uma particularidade, apesar de os animais serem menores, eles possuem grande circunferência torácica, o que pode estar relacionado à necessidade de ingestão de matéria seca ou ao fato de terem maior aptidão para corte.

Em posse das medidas biométricas, encontrou-se diversidade fenotípica dentro da raça Santa Inês (Tabela 4) e, posteriormente, deve-se averiguar as causas dessa diversidade sendo que a própria formação da raça, do isolamento geográfico e atuação da seleção natural ou através de cruzamento com raças especializadas estão entre as possíveis explicações. 
Tabela 4. Numero de animais (N), médias e desvios padrão (DP) das medidas corporais de ovinos da raça santa Inês nos municípios do Estado do Piauí

\begin{tabular}{|c|c|c|c|c|c|c|c|c|c|c|c|}
\hline \multirow[t]{2}{*}{ Municípios } & \multicolumn{3}{|c|}{ Altura Garupa } & \multicolumn{2}{|c|}{$\begin{array}{c}\text { Altura } \\
\text { Cernelha }\end{array}$} & \multicolumn{2}{|c|}{$\begin{array}{c}\text { Comprimento } \\
\text { Corporal }\end{array}$} & \multicolumn{2}{|c|}{$\begin{array}{c}\text { Comprimento } \\
\text { Orelha }\end{array}$} & \multicolumn{2}{|c|}{$\begin{array}{l}\text { Circunferência } \\
\text { Torácica }\end{array}$} \\
\hline & $\mathrm{N}$ & Média & $\mathrm{DP}$ & Média & DP & Média & $\mathrm{DP}$ & Média & DP & Média & DP \\
\hline Angical & 18 & $77,65^{\mathrm{a}}$ & 5,95 & $77,29^{a}$ & 3,85 & $75,12^{a}$ & 6,76 & $17,71^{\mathrm{a}}$ & 1,53 & $95,00^{\mathrm{a}}$ & 6,04 \\
\hline Aroazes & 66 & $70,42^{\mathrm{cd}}$ & 3,44 & $71,43^{\text {cde }}$ & 3,70 & $69,22^{\mathrm{cd}}$ & 3,34 & $15,30^{\mathrm{d}}$ & 2,10 & $81,14^{\mathrm{ef}}$ & 4,68 \\
\hline Bom Jesus & 194 & $71,87^{\mathrm{bc}}$ & 4,16 & $70,95^{\mathrm{de}}$ & 4,63 & $68,53^{\mathrm{cd}}$ & 5,73 & $15,85^{\text {bcd }}$ & 1,69 & $85,27^{\text {cde }}$ & 9,09 \\
\hline Campo Maior & 178 & $71,82^{\mathrm{bc}}$ & 4,25 & $72,90^{\mathrm{bc}}$ & 4,04 & $72,06_{a b c}$ & 6,77 & $16,61^{\mathrm{b}}$ & 1,36 & $86,97^{\mathrm{cd}}$ & 9,45 \\
\hline Cristino Castro & 80 & $73,17^{\mathrm{bc}}$ & 3,25 & $73,73^{b c}$ & 2,88 & $71,51^{\mathrm{abc}}$ & 4,22 & $16,66^{\mathrm{b}}$ & 1,70 & $85,76^{\mathrm{cde}}$ & 5,50 \\
\hline Dirceu Arcoverde & 30 & $65,34^{\mathrm{f}}$ & 5,04 & $59,69^{g}$ & 2,76 & $62,98^{\mathrm{e}}$ & 4,07 & $12,24^{\mathrm{f}}$ & 1,37 & $89,69^{\mathrm{bcd}}$ & 9,97 \\
\hline Elesbão Veloso & 38 & $68,71^{\mathrm{de}}$ & 2,66 & $70,45^{\mathrm{de}}$ & 2,50 & $69,24^{\mathrm{cd}}$ & 3,40 & $15,37^{\mathrm{d}}$ & 1,75 & $90,71^{\mathrm{abc}}$ & 4,42 \\
\hline Floriano & 44 & $73,16^{\mathrm{bc}}$ & 4,04 & $73,75^{\mathrm{bc}}$ & 4,37 & $72,28^{\mathrm{abc}}$ & 5,96 & $16,07^{\mathrm{bcd}}$ & 1,54 & $89,31^{\text {bcd }}$ & 7,45 \\
\hline Palmeira do Piauí & 30 & $67,82^{\mathrm{e}}$ & 6,86 & $68,58^{\mathrm{e}}$ & 6,91 & $62,31^{\mathrm{e}}$ & 7,89 & $12,79^{\mathrm{f}}$ & 1,56 & $80,83^{\mathrm{ef}}$ & 10,91 \\
\hline Piracuruca & 34 & $69,09^{\mathrm{de}}$ & 5,78 & $69,38^{\mathrm{e}}$ & 5,06 & $65,74^{\mathrm{d}}$ & 6,01 & $16,38^{\mathrm{bc}}$ & 2,45 & $80,38^{\mathrm{ef}}$ & 8,69 \\
\hline Redenção do Gurguéia & 36 & $71,29^{\text {bcd }}$ & 4,63 & $71,23^{\text {cde }}$ & 4,78 & $73,82^{\mathrm{ab}}$ & 3,75 & $16,86^{\mathrm{b}}$ & 1,37 & $84,29^{\mathrm{de}}$ & 6,66 \\
\hline $\begin{array}{l}\text { Santa Cruz dos } \\
\text { Milagres }\end{array}$ & 48 & $64,53^{\mathrm{f}}$ & 3,94 & $65,71^{\mathrm{f}}$ & 3,61 & $66,66^{d}$ & 4,90 & $14,29^{\mathrm{e}}$ & 1,57 & $77,24^{\mathrm{f}}$ & 5,01 \\
\hline São Pedro & 18 & $70,52^{\mathrm{cd}}$ & 4,54 & $69,34^{\mathrm{e}}$ & 4,48 & $72,28^{\mathrm{abc}}$ & 6,53 & $15,55^{\mathrm{cd}}$ & 1,20 & $81,74^{\mathrm{ef}}$ & 9,07 \\
\hline São Raimundo Nonato & 55 & $73,13^{b c}$ & 3,75 & $70,25^{\mathrm{de}}$ & 5,40 & $70,72^{\mathrm{bc}}$ & 8,67 & $14,34^{\mathrm{e}}$ & 1,83 & $88,65^{\mathrm{cd}}$ & 10,35 \\
\hline Teresina & 108 & $73,82^{\mathrm{b}}$ & 4,20 & $74,11^{\mathrm{b}}$ & 4,97 & $74,24^{\mathrm{ab}}$ & 6,01 & $16,59^{\mathrm{b}}$ & 1,56 & $94,05^{\mathrm{ab}}$ & 10,96 \\
\hline
\end{tabular}

Médias seguidas de mesma letra na coluna não diferem $(\mathrm{P}>0,05)$ pelo teste Student-Newman-Keuls 
Devido à dificuldade de analisar e interpretar todas as características biométricas isoladamente optou-se pela análise multivariada. Inicialmente, executou-se a análise de componentes principais, a obtenção da média de cada município e análise da variabilidade explicada pelos componentes estimados. Os dois primeiros componentes principais explicaram 90,95\% da variação total, demonstrando que a técnica de componente principal foi efetiva para reduzir a dimensionalidade dos dados, possibilitando a análise em um plano cartesiano, ou seja, bidimensional, simultaneamente, sem a perda de informação.

Apesar de a análise ter gerado cinco componentes principais, os dois primeiros componentes explicam mais de $90 \%$ da variabilidade, sendo que o primeiro componente explica $75 \%$ da variação total e o segundo aproximadamente $15 \%$, tornando, assim, os demais componentes passíveis de descarte. Segundo Campana (2010), as variáveis de maiores pesos nos primeiros autovetores são consideradas de maior importância para o estudo de diversidade, quando o autovalor explica uma fração considerável da variação disponível, normalmente limitada em valor mínimo de $80 \%$. Dos cinco componentes principais, três $(60 \%)$ apresentam variância inferior a 0,7 (autovalor inferior a 0,7) e estariam aptos a serem descartados.

Os resultados encontrados na análise de componentes principais estão de acordo com Carneiro et al. (2010), já que o primeiro componente principal foi altamente influenciado pelas características de altura e comprimento, mostrando que as medidas do tamanho do animal devem ser consideradas em estudos de diversidade e caracterização dos animais.

Ao estudar os componentes principais pode-se plotar os escores relativos referentes aos dois primeiros componentes em um gráfico, o que permite a visualização gráfica dos escores relativos a cada município de criação para os dois primeiros componentes (Figura 3).

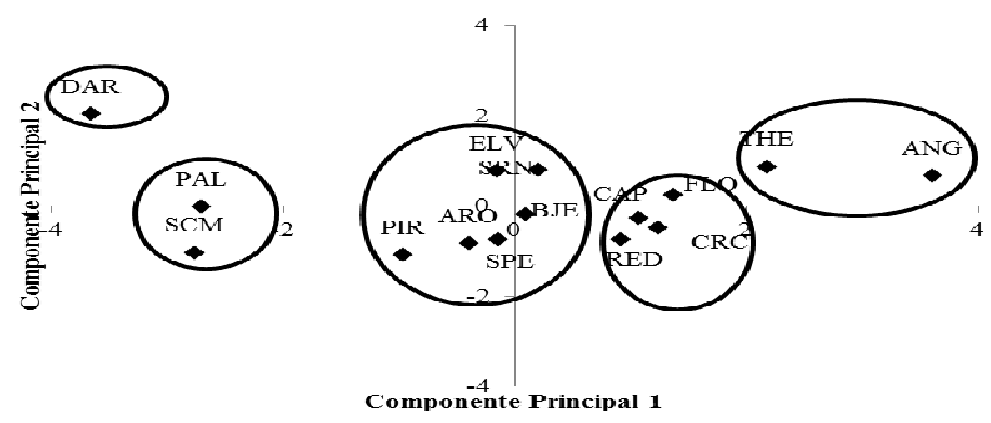

DAR:Dirceu Arcoverde; PAL: Palmeira do Piauí; SCM:Santa Cruz dos Milagres; PIR:Piaracuruca; ARO:Aroazes; SRN:São Raimundo Nonato; ELV:Elesbão Veloso; BJE:Bom Jesus; SPE:São Pedro do Piauí; RED:Redenção do Gurguéia; CAP:Campo Maior; FLO:Floriano; CRC:Cristino Castro; THE:Teresina; ANG:Angical

Figura 3. Dispersão dos municípios criadores de Santa Inês em função dos dois primeiros componentes principais a partir de características biométricas 
Percebe-se que as distribuições dos municípios no gráfico estão de maneira que pode-se agrupá-los em municípios com maiores similaridade (mais próximos quanto à visualização gráfica), como o caso dos municípios de Palmeira do Piauí e Santa Cruz dos Milagres, o que sugere a formação de um grupo; além dos animais criados em Aroazes, Bom Jesus, Elesbão Veloso, Piracuruca, São Pedro e São Raimundo Nonato comporem um segundo agrupamento; os criados nos municípios de Campo Maior, Cristino Castro, Floriano e Redenção do Gurguéia, um terceiro grupo; os animais pertencentes aos municípios de Teresina e Angical, um quarto grupo, e, um quinto e último grupo composto somente pelos animais criados no município de Dirceu Arcoverde.

A utilização dos componentes principais para a formação dos grupos de animais é feita de forma empírica a partir da visualização gráfica, que pode acometer distorções de distâncias entre os grupos. Assim optou-se pela análise de agrupamento.

A diversidade verificada com a análise de componente principal foi comprovada pela análise de agrupamento pelo método Ward, na qual são agrupados os indivíduos criados em municípios mais similares entre si (Figura 4). O método de Ward é baseado na noção de que os grupos de observações multivariadas devem ser agrupadas, aproximadamente, numa elipse. É um método hierárquico precursor de métodos de agrupamentos não hierárquicos que aperfeiçoam algum critério para dividir os dados em certo número de grupos elípticos. Neste método, consideram-se, para a formação inicial do grupo, aqueles indivíduos que proporcionam a menor soma de quadrado dos desvios.

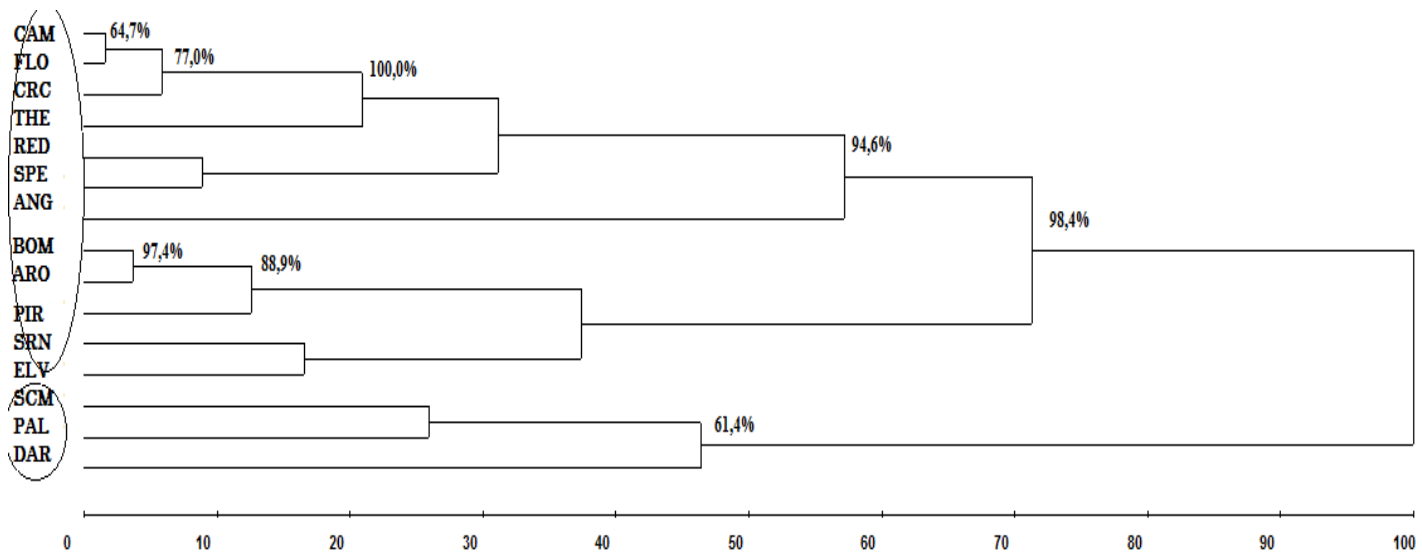

DAR:Dirceu Arcoverde; PAL: Palmeira do Piauí; SCM:Santa Cruz dos Milagres; PIR:Piaracuruca; ARO:Aroazes; SRN:São Raimundo Nonato; ELV:Elesbão Veloso; BJE:Bom Jesus; SPE:São Pedro do Piauí; RED:Redenção do Gurguéia; CAP:Campo Maior; FLO:Floriano; CRC:Cristino Castro; THE:Teresina; ANG:Angical

Figura 4. Dendrograma do agrupamento dos animais pertencentes aos municípios do Estado do Piauí pelo método Ward em função das medidas corporais com os valores e bootstrap acima de $50 \%$ indicados em cada nó 
Os valores de bootstrap acima de 50\% demonstram confiança na formação dos nódulos do dendograma apresentado, visto que os dados são variáveis contínuas e há variabilidade entre os indivíduos.

Através dos dendrogramas, que representam a similaridade genética das populações pelo método de Ward, houve formação de dois grupos com animais similares dentro de cada grupo e diferentes entre os grupos. $\mathrm{O}$ grupo um foi formado pelos indivíduos pertencentes aos municípios de Angical, Aroazes, Bom Jesus, Campo Maior, Cristino Castro, Elesbão Veloso, Floriano, Piracuruca, Redenção do Gurguéia, São Pedro, São Raimundo Nonato e Teresina, com bootstrap superior a 98\%; o segundo grupo, formado por indivíduos dos municípios de Dirceu Arcoverde, Palmeira do Piauí e Santa Cruz dos Milagres, apresentou bootstrap superior a $60 \%$.

Quanto à avaliação do grau de ajuste entre as matrizes de dissimilaridade e as matrizes resultantes dos agrupamentos, para a formação dos dendrogramas, foi estimado o coeficiente de correlação cofenética (CCC) igual a 0,71. Quanto maior o valor do coeficiente, menor é a distorção provocada para agrupar as populações. A partir desses coeficientes, conclui-se que a distância euclidiana média padronizada foi adequada para resumir a informação do conjunto de dados, conforme sugerido por Rohlf (1970).

Comparando as médias de cada grupo (Tabela 5), pode-se verificar, em relação às medidas corporais, que os animais pertencentes ao grupo 1 possuem maior tamanho corporal, talvez favorecido pela localização próxima aos grande centros em que a tecnologia é bastante difundida e a intervenção do homem nos manejos reprodutivo e alimentar é visível, além da possível utilização de reprodutores de raças importadas em esquemas de cruzamentos, o que é mais evidente, dadas as rápidas mudanças que vêm acontecendo nos últimos anos.

Tabela 5. Médias para as características biométricas de ovinos da raça Santa Inês encontrados nos diferentes grupos segundo análise de agrupamento pelo método Ward

\begin{tabular}{|c|c|c|c|c|c|c|}
\hline \multirow[t]{2}{*}{ Grupos } & \multirow[t]{2}{*}{ Municípios } & $\begin{array}{c}\text { Altura } \\
\text { cernelha }\end{array}$ & $\begin{array}{l}\text { Altura } \\
\text { garupa }\end{array}$ & $\begin{array}{c}\text { Comprimento } \\
\text { corporal }\end{array}$ & $\begin{array}{c}\text { Comprimento } \\
\text { orelha }\end{array}$ & $\begin{array}{l}\text { Circunferênci } \\
\text { a torácica }\end{array}$ \\
\hline & & Média & Média & Média & Média & Média \\
\hline 1 & $\begin{array}{l}\text { Angical, Aroazes, } \\
\text { Bom Jesus, Campo } \\
\text { Maior, Cristino } \\
\text { Castro, Elesbão } \\
\text { Veloso, Floriano, } \\
\text { Piracuruca, } \\
\text { Redenção do } \\
\text { Gurguéia, São } \\
\text { Pedro, São } \\
\text { Raimundo Nonato } \\
\text { e Teresina }\end{array}$ & $72,14^{\mathrm{a}}$ & $72,07^{\mathrm{a}}$ & $70,98^{\mathrm{a}}$ & $16,12^{\mathrm{a}}$ & $86,98^{\mathrm{a}}$ \\
\hline 2 & $\begin{array}{l}\text { Dirceu Arcoverde, } \\
\text { Palmeira do Piauí } \\
\text { e Santa Cruz dos } \\
\text { Milagres }\end{array}$ & $64,85^{\mathrm{b}}$ & $65,66^{\mathrm{b}}$ & $64,46^{\mathrm{b}}$ & $13,32^{\mathrm{b}}$ & $81,63^{b}$ \\
\hline
\end{tabular}

Médias seguidas de mesma letra na coluna não diferem $(\mathrm{P}>0,05)$ pelo teste Student-Newman-Keuls 
Enquanto que no segundo grupo, os animais apresentam menores medidas em relação aos animais do primeiro, ou seja, são animais de menor porte, que estão sendo criados em municípios com maior isolamento geográfico e em condições climáticas mais adversas, com baixa intervenção do homem na seleção e, possivelmente, sem a utilização de animais especializados na produção de carne. Esses grupos formados tendem a apresentar animais semelhantes dentro de grupos e dessemelhantes entre grupos.

Existem diferentes tipos de ovinos Santa Inês criados no Estado do Piauí. As populações das oito microrregiões analisadas apresentam características diferenciadas entre si. Constatou-se a formação de dois grupos distintos de animais, com tendência dos grupos apresentarem animais de maior porte e de menor porte;

As diferentes metodologias multivariadas entre as populações ovinas tanto para as microrregiões e municípios foram concordantes quanto à existência de diversidade dentro da raça Santa Inês e auxiliou no processo de caracterização da raça.

\section{REFERÊNCIAS}

ASSOCIAÇÃO BRASILEIRA DE CRIADORES DE OVINOS - ARCO. $<$ http://www.arcoovinos.com.br/ racas_links.html >. Acesso em: 20 novembro de 2011.

BARBOSA, L.T.; REGAZZI, A.J.; BACKES, A.A.; FAGUNDES, J.L.; VIERA, J.S.; MORAIS, J.A.S. Associação entre qualidade da carne e características quantitativas de suínos por meio de correlação canônica.

Revista Brasileira de Saúde e
Produção Animal [online], v.11, n.4, p.1150-1162, 2010.

BUENO, M.S.; CUNHA, E.A; SANTOS, L.E. Características de carcaça de ovinos Santa Inês abatidos com diferentes idades. Archivos de Zootecnia, v.50, p.33-38, 2002.

CARNEIRO, H.; LOUVANDINI, H.; PAIVA, S.R.; MACEDO, F.; MERNIES, B.; McMANUS, C. Morphological characterization of sheep breeds in Brazil, Uruguay and Colombia. Small Ruminant Research, v.94, p.58-65, 2010.

COSTA JÚNIOR, G.S.; CAMPELO, J.E.G.; AZEVÊDO, D.M.M.R.; MARTINS FILHO, R.; CAVALCANTE, R.R.; LOPES, J.B.; OLIVEIRA, M.E. Caracterização morfométrica de ovinos da raça Santa Inês criados nas microrregiões de Teresina e Campo Maior, Piauí. Revista Brasileira de Zootecnia, v.35, n.6, p.2260-2267, 2006.

\section{CAMPANA, A.C.M.; RIBEIRO}

JÚNIOR, J.I.; NASCIMENTO, M. Uma proposta de transformação de dados para análise de componentes principais.

Revista Brasileira de Biometria, v.28, n.2, p.103-115, 2010.

DOSSA, L.H.; WOLLNY, C.; GAULY, M. Spatial variation in goat population from Benin as reveled by multivariate analysis of morphological traits. Small Ruminant Research, v.73, p.150-159, 2007.

OLIVEIRA, J.C.V. de; ROCHA, L.L. da; RIBEIRO, M.N.; GOMES FILHO, M.A. Caracterização e perfil genético visível de caprinos Nativos no Estado de Pernambuco. Archivos de Zootecnia, v.55, n.209, p.63-73, 2006. 
PAIVA, S.R.; SILVÉRIO, V.C.;

EGITO, A.A.; MCMANUS, C.;

FARIA, D.A.; MARIANTE, A.S.;

CASTRO, S.R.; ALBUQUERQUE, M.S.M.; DERGAM, J.A. Genetic variability of the Brazilian hair sheep breeds. Revista Agropecuária

Brasileira, v.40, n.9, p.887-893, 2005.

RENCHER, A.C. Methods of multivariate analysis. $2 \mathrm{t}^{\mathrm{h}}$ ed. New York: Wiley-interscience, 2002. 708p.

ROHLF, F.J. Adaptative hierarquical clustering schemes. Systematic Zoology, v.19, n.1, p.58-82, 1970.

SAS Institute. User's guide: statisticsversion, Cary, 2002.
SILVA, N.V.; FRAGA, A.B.; ARAÚJO FILHO, J.T.; CAVALCANTI NETO, C.C.; SILVA, F.L.; COSTA, P.P.S.; LIRA JÚNIOR, W.B. Caracterização morfométrica de ovinos deslanados Cabugi e Morada Nova. Revista de Ciência e Produção Animal, v.9, n.1, p.65-75, 2007.

SOKAL, R.A.; ROHLF, F.J. The comparison of dendograms by objective methods. Taxonomy, v.11, p.33-40, 1962.

Data de recebimento: 18/04/2012

Data de aprovação: 13/12/2012 